\title{
Population dynamics and genetic differentiation in the bivalve mollusc Abra tenuis: aplanic dispersal
}

\author{
Sebastian P. Holmes*', Robert Dekker, Ivor D. Williams \\ Nederlands Instituut voor Onderzoek der Zee (NIOZ), Postbus 59, 1790 AB, Den Burg, Texel, The Netherlands
}

\begin{abstract}
The bivalve mollusc Abra tenuis is an aplanic (directly developing) species occupying a discontinuous (fragmented) habitat in the high intertidal area of mudflats. In view of its mode of reproduction and habitat, populations of $A$. tenuis should exhibit temporal stability and be genetically dissimilar. Examination of the population dynamics of A. tenuis, at 2 sites in the Dutch Western Wadden Sea over the last $29 \mathrm{yr}$, has revealed that population densities fluctuate wildly from year to year, and that there have been 2 'apparent' local extinction events, one of which lasted for 3 yr. Investigation into the population genetics of Abra tenuis in the Dutch Western Wadden Sea, using random amplified polymorphic DNA (RAPD) analysis, both at the macro $(\geq 2 \mathrm{~km})$ and microscale $(\geq 30 \mathrm{~m})$, determined that 6 of the 7 studied populations formed 3 groups that were genetically homogenous within a group, but genetically distinct from each other. This included a group pair where the distance of geographical separation was $\sim 3 \mathrm{~km}$. The 7 th population was genetically distinct from all other population groups. While there is some degree of genetic differentiation among populations, given both the population genetics and dynamics results, it is evident that dispersal has occurred among some populations.
\end{abstract}

KEY WORDS: Aplanic $\cdot$ Abra tenuis $\cdot$ Dispersal $\cdot$ Metapopulation $\cdot$ Panmixia $\cdot$ Population dynamics $\cdot$ RAPD $\cdot$ Reproduction

Resale or republication not permitted without written consent of the publisher

\section{INTRODUCTION}

The production of a broadcast (dispersal) stage has been dubbed an essential feature of the life history of many sessile marine invertebrates (Crisp 1976). As such, dispersal has been commonly assumed to ensure the following: (1) that unpredictably located habitats are colonized (Lewontin 1965, Farrell 1991, Menge 1995); (2) that local competition is reduced (Istock 1967, Menge 1975, Havenhand 1995); and (3) that concentrations of predators are avoided (Pechenik 1979, Gaines \& Lafferty 1995; Lindquist \& Hay 1996) (see Pechenik 1999 for review). Consequently, the level of gene flow that exists between populations has often been equated with the ability of an organism to disperse, and ultimately its mode of reproduction (Palumbi 1995). This presumption that the mode of reproduction reflects the dispersal capacity of an organism, and hence its population genetics, forms the precept for the panmictic model. That is, species that produce directly-developing (aplanic), e.g. Littorina obtusata, L. mariae, L. saxatilis and Calliostoma zizyphinum (intertidal gastropods and a subtidal gastropod), or short-lived (anchiplanic) larvae, e.g. Nucula nitidosa, Turritella communis, Spirorbis spirorbis (a sub-tidal bivalve, a sub-tidal gastropod and an intertidal polychaete), will have a very limited dispersal capacity with genetically distinct populations, whereas the reverse will be true for species that produce longlived (actae/teleplanic) planktotrophic larvae, e.g. Semibalanus balanoides, Arctica islandica and Macoma balthica (an intertidal crustacean, a sub-tidal and an intertidal bivalve) (Todd \& Doyle 1981, Wray \& Raff 1991, Havenhand 1995). Put simply, a/anchiplanic species, in genetic terms, will have locally genetically homogenous, but globally genetically heterogeneous, populations, whilst actae/teleplanic species will have locally genetically heterogeneous, but globally geneti- 
cally homogenous, populations (see Gooch et al. 1972, Gaines et al. 1974, Palumbi \& Kessing 1991, Hunt 1993, Huang et al. 2000, Kim et al. 2000 for examples).

The bivalve mollusc Abra tenuis lives in fine muddy sand, in the high intertidal area of mudflats and estuaries. It occurs from the west coast of Scotland and Northumberland down through both the North Sea and Atlantic coasts to Mauritania (Tebble 1966, Campbell 1985). Sexes are separate (dioecious), with reproduction occurring externally from July to September, depending on location, to produce egg masses (400 to 1800 eggs, 4 to $6 \mathrm{~cm}$ long, $2 \mathrm{~cm}$ diameter) which are laid directly into the uppermost layer of the sediment surface. The developing juveniles $(\sim 0.2 \mathrm{~mm}$ shell length) then hatch directly some 2 to 3 wk later, i.e. A. tenuis is an aplanic species (Nott 1980, Gibbs 1984, Bachelet 1989). Juveniles grow very slowly for the first 6 mo, during which time shell length increases by $\sim 0.3 \mathrm{~mm}$, with considerable mortality (>98\%), followed by a rapid burst of growth in spring, whereupon the majority of individuals have become sexually mature and attained a shell length of $\sim 4 \mathrm{~mm}$ by the summer (Nott 1980, Gibbs 1984, Bachelet 1989). Longevity is thought to be of the order of $2 \mathrm{yr}$ (Nott 1980, Gibbs 1984, Bachelet 1989, Dekker \& Beukema 1993). In terms of its physiology/adaptation, A. tenuis can withstand extremely low salinities $(<4 \%)$, prolonged exposure (>10 d) (Gibbs 1984), and severe hypoxia, with the ability to reduce its metabolism to $6 \%$ of that under normoxia (Wang \& Widdows 1993). Normal adult densities are of the order of 300 to 1500 ind. $\mathrm{m}^{-2}$, with mature specimens reaching a maximal size of $10 \mathrm{~mm}$ (shell length) (Gibbs 1984, Bachelet 1989, Dekker \& Beukema 1999). Populations of $A$. tenuis can be extremely susceptible ( $\leq 100 \%)$ to infection by Digenean parasites, rendering the hosts infertile (Gibbs 1984, Campbell 1985). In terms of functional strategy, given its habitat, size and mode of reproduction, we would consider it to be representative of a 'conservationist' (i.e. a species where investment in growth, metabolism and reproduction is low (univoltine) in order sustain maintenance in a resourcelimited habitat) rather than an 'exploitative' species (i.e. a species where investment in growth, metabolism and reproduction [multivoltine] is high, in a habitat with abundant resources; Holmes et al. 2002).

Given that Abra tenuis is an aplanic species, it would be reasonable to assume that they maintain stable population levels (Thorson 1950, Mileikovsky 1971, Van der Meer et al. 2001) and under a panmictic model, examination of the long-term population dynamics of this species should show consistent stability with no local extinction events. Correspondingly, examination of the population genetics of this species should reveal distinct populations with no gene-flow (recruitment) between sites. The aims of this paper are as follows: (1) to determine if the population dynamics of Abra tenuis are consistent with those that would be expected from their mode of reproduction, i.e. inherently stable populations with no extinction events; and (2) to examine the population genetics of Abra tenuis and ascertain whether they correlate with the data obtained on their population dynamics, and conform to the expectations derived from the panmictic model.

\section{MATERIALS AND METHODS}

Population dynamics. The population dynamics of Abra tenuis were studied at Balgzand (Western Wadden Sea, North Holland) along 2 permanent 1 km transects, running parallel to each other from the highwater mark to mean mid-tide level (Table 1, Fig. 1). Full details on the intertidal elevation and sediment

Table 1. Locations of Abra tenuis populations. NA: not applicable

\begin{tabular}{|c|c|c|c|c|}
\hline Collection site & Latitude & Longitude & Code & $\begin{array}{l}\text { No. of specimens collected } \\
\text { for genetic analysis }\end{array}$ \\
\hline \multicolumn{5}{|l|}{ Transects } \\
\hline Transect 1 start & $52: 53: 532 \mathrm{~N}$ & 04:51:792 E & 1 & NA \\
\hline finish & $52: 54: 044 \mathrm{~N}$ & 04:51:755 E & & NA \\
\hline Transect 2 start & $52: 54: 038 \mathrm{~N}$ & 04:50:355 E & 2 & NA \\
\hline finish & $52: 54: 038 \mathrm{~N}$ & 04:50:355 E & & NA \\
\hline \multicolumn{5}{|l|}{ Populations } \\
\hline Sluice T1 & $52: 58: 893 \mathrm{~N}$ & 04:47:805 E & $\mathrm{T} 1$ & 35 \\
\hline Sluice T3 & $52: 56: 292 \mathrm{~N}$ & $04: 47: 842 \mathrm{E}$ & T3 & 35 \\
\hline Sluice T3 - 30 m & $52: 56: 302 \mathrm{~N}$ & $04: 47: 813 \mathrm{E}$ & $\mathrm{T} 3-30$ & 24 \\
\hline Sluice T3 + 100 m & $52: 56: 275 \mathrm{~N}$ & 04:47:923 E & $\mathrm{T} 3+100$ & 35 \\
\hline Sluice T5 & $52: 56: 389 \mathrm{~N}$ & $04: 47: 925 \mathrm{E}$ & T5 & 35 \\
\hline Vogel & $52: 24: 969 \mathrm{~N}$ & 04:48:230 E & $\mathrm{V}$ & 35 \\
\hline Mok & $53: 00: 323 \mathrm{~N}$ & 04:45:035 E & M & 35 \\
\hline
\end{tabular}


composition of these transects (Transects 1 and 2) can be found in Beukema (1993) and Dekker \& Beukema (1993). The transects were sampled, as detailed in Dekker \& Beukema (1993), twice annually (in March and August) from March 1974 to August 2002 (ongoing). A. tenuis with a shell length $>1 \mathrm{~mm}$ were sampled with a $1 \mathrm{~mm}$ square mesh size sieve. Hence, only data for individuals $\geq 1$ yr old are presented (see Bachelet 1989, Dekker \& Beukema 1993). Samples were pooled over each transect and their entire lengths (see Dekker \& Beukema 1993). In addition, shell lengths were measured, to the nearest $0.1 \mathrm{~mm}$, and classified as follows, for the samples obtained in March: (a) individuals $>4<7 \mathrm{~mm}$ were considered to be representative of the 1st year-class cohort (i.e. 19 mo old); (b) individuals $>7<9 \mathrm{~mm}$ representative of the 2 nd year-class cohort (i.e. $~ 31 \mathrm{mo}$ old). For the samples collected in August: (a) individuals $>3.5<6 \mathrm{~mm}$ representative of the $1 \mathrm{st}$ year-class ( 12 mo old); (b) individuals $>6<8 \mathrm{~mm}$ representative of the 2 nd year-class cohort $(\sim 24 \mathrm{mo}$ old); (c) individuals $>8$ representative of the 3rd yearclass cohort (see Dekker \& Beukema 1993). All density estimates are given as no. $\mathrm{m}^{-2}$, derived from pooled data for each transect.

Population genetics. Adult ( $>4 \mathrm{~mm}$, Gibbs 1984) Abra tenuis ( $\geq 24$ individuals), covering a range of cohorts, were collected by hand from 3 different sites in the Dutch Western Wadden Sea in 2002 (Table 1, Fig. 1). At the largest site (sluice) the population was divided into 5 sub-populations (see Table 1, Fig. 1). Once collected, all specimens were immediately frozen $\left(-80^{\circ} \mathrm{C}\right)$ and stored at $-20^{\circ} \mathrm{C}$ for future processing.

Total DNA extractions, RAPD PCR protocol and fragment identification. Total DNA extractions: DNA extraction was made using a commercially available kit (Quantum Prep AquaPure Genomic DNA, Bio-Rad Laboratories) under a modified extraction protocol as follows: (1) approximately $2 \mathrm{mg}$ of frozen posterior adductor muscle was removed from each specimen and placed into $1.5 \mathrm{ml}$ eppendorf tube, on ice, containing $150 \mu \mathrm{l}$ of lysis solution; (2) samples were then homogenised using a micro pestle, and $0.75 \mu$ l of Proteinase $\mathrm{k}\left(20 \mathrm{mg} \mathrm{ml}^{-1}\right)$ was added and the solution was placed in a water bath for $12 \mathrm{~h}$ at $55^{\circ} \mathrm{C}_{\text {; }}$ (3) $0.75 \mu \mathrm{l}$ RNase was then added and the solution was incubated for a further $45 \mathrm{~min}$ at $65^{\circ} \mathrm{C}_{i}(4)$ following this the samples were cooled to room temperature and $100 \mu \mathrm{l}$ Protein Precipitation Solution was added; (5) the samples were then vortexed for $20 \mathrm{~s}$, centrifuged at $14000 \times g$ for $3 \mathrm{~min}$ and the resulting supernatant poured off into a fresh eppendorf tube containing $150 \mu \mathrm{l} 100 \%$ Isopropanol, and mixed by gently by inverting 50 times; (6) following this, the samples were centrifuged again at $14000 \times g$ for $1 \mathrm{~min}$, the resulting supernatant

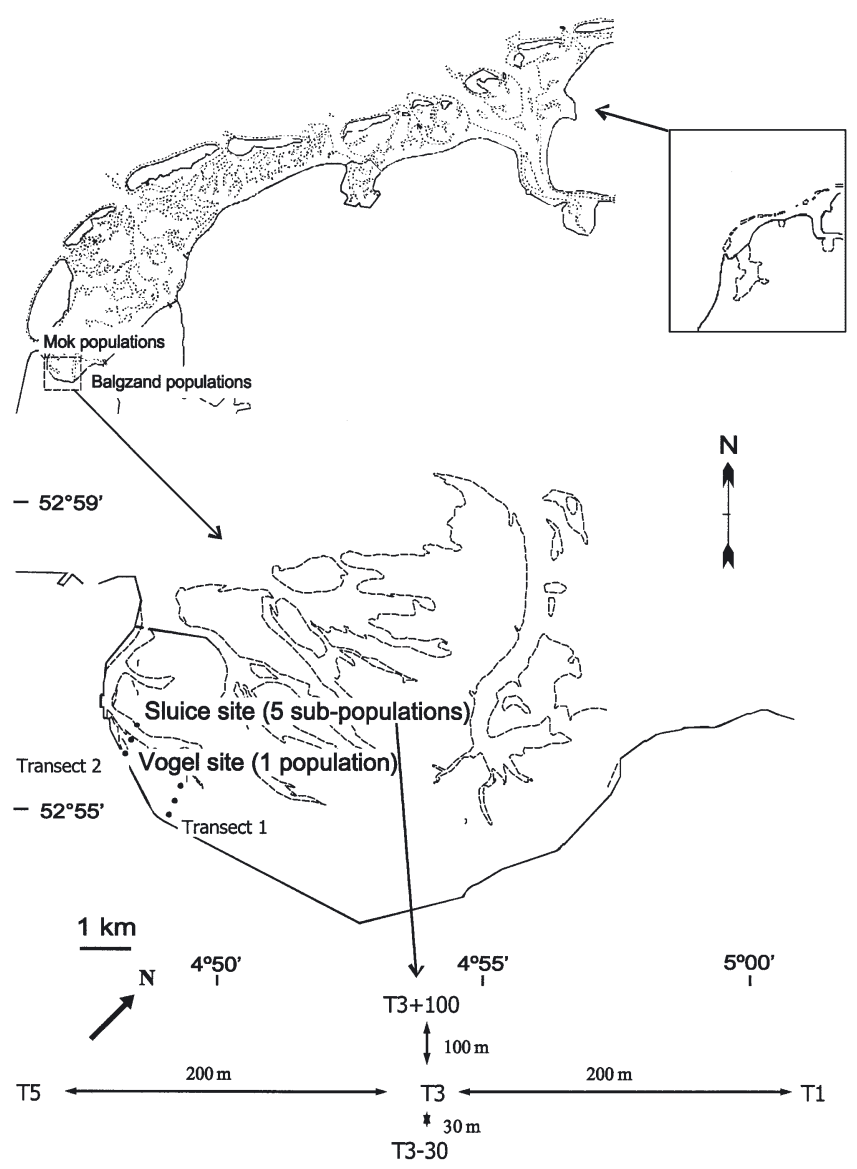

Fig. 1. Location of source Abra tenuis populations

poured off and the remaining pellet washed in $150 \mu \mathrm{l}$ of $70 \%$ ethanol by inverting the sample several times; (7) Step 6 was repeated once more, the supernatant poured off and samples left to air dry for $1 h_{i}(8) 50 \mu l$ of DNA hydration buffer was then added to the airdried pellets and the samples were left to rehydrate overnight at room temperature.

All samples were stored on ice until the proceeding step. Once hydrated, each DNA sample was split $(2 \times$ $25 \mu \mathrm{l}$ in eppendorf tubes) and stored at $-20^{\circ} \mathrm{C}$ for future use.

RAPD-PCR protocol: Initially, a random selection of 20 individual DNA samples, in 1:1, 1:10, 1:100, 1:1000, and 1:10000 dilutions, were tested using a series of 25 different $10 \mathrm{bp}$ primers (Thermo Hybaid). From these runs, a DNA dilution of 1:100 was selected, as this dilution produced the best results both within and between populations, and a set of 6 primers were selected for further use (Table 2). All amplifications were made in a $25 \mu$ volume reaction mix, in a $100 \mu \mathrm{l}$ reaction tube, made up as follows: $0.75 \mu \mathrm{l}$ (0.75 units) of Redtag DNA polymerase (Sigma); $2.5 \mu \mathrm{l}$ of Redtaq PCR 
Table 2. Primers and number of cycles for the second step of the amplification procedure

\begin{tabular}{|lccccc|}
\hline Primer label & Sequence $\left(5^{\prime}-3^{\prime}\right)$ & \% GC & No. 2nd-step cycles & Total bands produced & No. polymorphic bands \\
\hline OPC04 & GGGAATTCGG & 60 & 35 & 9 & 7 \\
UBC212 & GCTGCGTGAC & 70 & 29 & 7 & 7 \\
OPG06 & GTGCCTAACC & 60 & 29 & 6 & 5 \\
OPR01 & TGCGGGTCCT & 70 & 29 & 13 & 6 \\
UBC145 & TGTCGGTTC & 60 & 35 & 6 & 11 \\
UBC150 & GGAGGCTCTG & 70 & 25 & & 14 \\
\hline
\end{tabular}

Table 3. Reaction sequence for RAPD-PCR protocol

\begin{tabular}{|lccccccccc|}
\hline & \multicolumn{3}{c}{ Step 1 } & \multicolumn{3}{c}{ Step 2 } & \multicolumn{3}{c|}{ Step 3 } \\
\hline Temp $\left({ }^{\circ} \mathrm{C}\right)$ & 94 & 36 & 72 & 94 & 36 & 72 & 94 & 36 & 72 \\
Duration (s) & 180 & 180 & 180 & 30 & 60 & 120 & 30 & 60 & 600 \\
No. of cycles & & 4 & & & $28-35$ & & $\infty$ & 1 \\
\hline
\end{tabular}

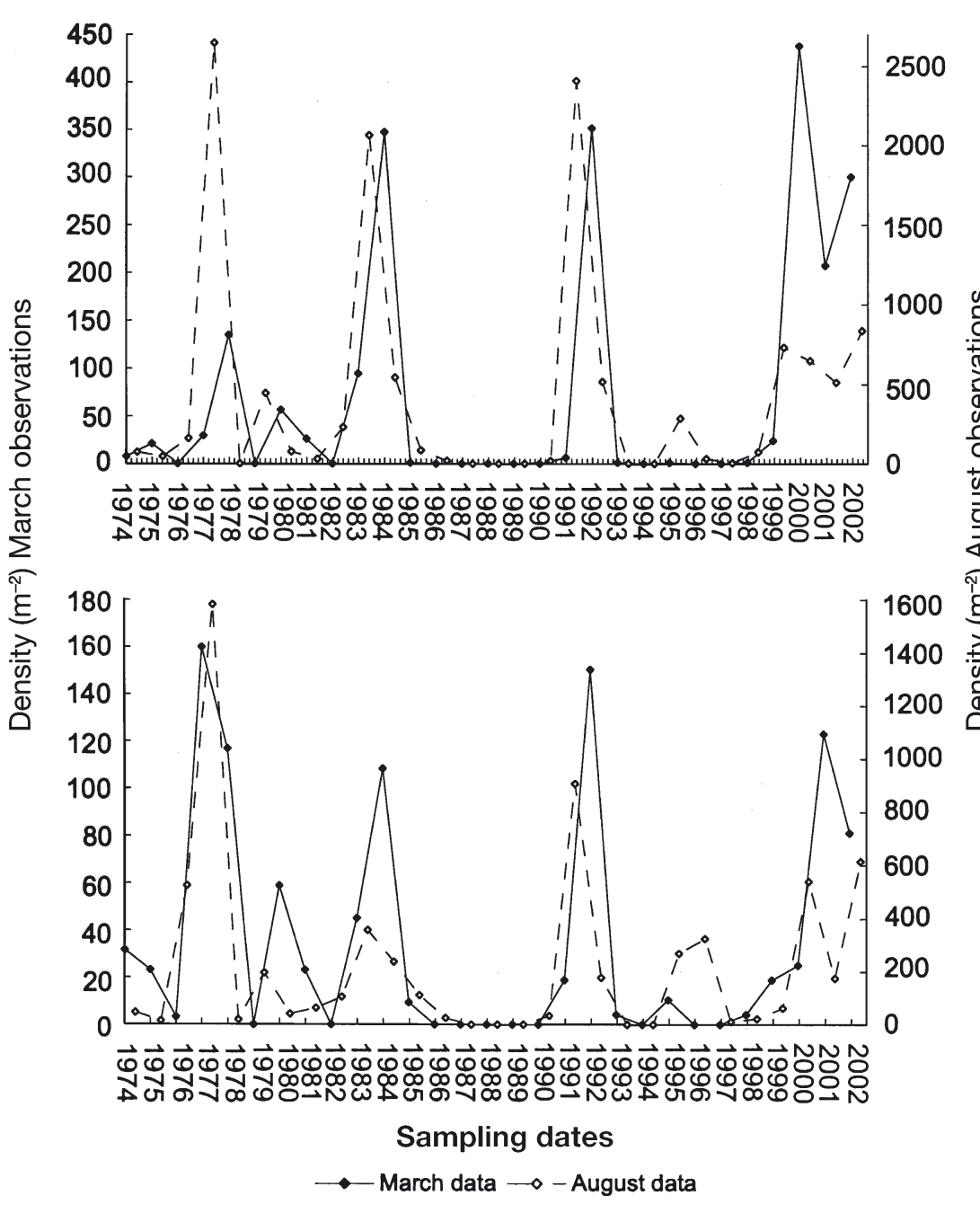

Fig. 2. Abra tenuis. Annual March and August densities in the 2 transects (data pooled) over the whole sampling period. (a) Transect 1 (b) Transect 2 reaction buffer; $1.0 \mu \mathrm{l}$ of DNTP $(5 \mathrm{mM})$; $0.5 \mu \mathrm{l}$ of primer $(1 \mathrm{mM}) ; 0.25 \mu$ l of tween20 (Pharmacia LKB biotechnology AB); $0.5 \mu$ of DNA dilution (made with 18 Megohm water [SIGMA] and $19.50 \mu \mathrm{l}$ of 18 Megohm water). The reaction sequence adopted is detailed in Table 3.

Because of problems with non-specific background products (see Palumbi 1996 for discussion), the number of cycles for the second step of the cycling sequence was optimised for each primer (see Table 2). Negative controls were run for each batch of reactions and contained no template DNA. All reactions were made in a 96-well Biometria T-gradient thermocycler (Biometria) and the samples randomly mixed for that primer between populations. The PCR products were made visible by gel electrophoresis, $\leq 7$ samples from each population for each primer per gel, on $1.5 \%, 10 \mathrm{~cm}$ path length, Agarose (Seakem LE Agarose, BioWitakker Molecular applications) gels. The gels were run in $1 \times$ Tris-borateEDTA (TBE) buffer at $10 \mathrm{~V} \mathrm{~cm}^{-1}$ for $90 \mathrm{~min}$. Three lanes of $100 \mathrm{bp}$ steps (100 to $3000 \mathrm{bp}$ ) molecular ladder (Superladder-mid1, Gensura) were included on every gel. The gels were stained for $30 \mathrm{~min}$ in Ethidium Bromide (0.001 $\mu \mathrm{g}$ $\left.\mathrm{ml}^{-1}\right)$, destained in $1 \times \mathrm{TBE}$ for $10 \mathrm{~min}$, and imaged using an UV imager. All bands between 100 and 2000 bp were scored for each primer and each sample, 
using the molecular ladder as a reference. Retrials were performed for each primer to ensure reproducibility between both PCR reaction conditions and gel resolution, with a randomly selected series of samples from all populations $(\mathrm{n}=26)$ revealing no discrepancies. If the results on a gel appeared to be erroneous, i.e. in comparison to existing samples, then a fresh gel was run and a repeat PCR amplification made for those samples.

RADP data analysis: Initially, a matrix of Euclidean (unsquared) phenotypic distances was calculated from the RAPD data $(n=234)$ and the resulting matrix subjected to a principal coordinates (PCO) analysis using MVSP (Ver. 3.13d, Kovach Computing Services) and the resulting factors plotted. The data were then analysed to test the population structure derived from the PCO with analysis of molecular variance (AMOVA) (Excoffier et al. 1992), using the ARLEQUIN package (Ver. 2; Schneider et al. 2000). One thousand random permutations of the data matrix were carried out to assess the significance of the variance components $\left(\Phi_{\mathrm{ST}}, \Phi_{\mathrm{CT}}\right.$ and $\left.\Phi_{\mathrm{SC}}\right)$ and of the pairwise variance $\left(\Phi_{\mathrm{ST}}\right)$ values for each grouping.

An unweighted pair-group mean arithmetic average (UPGMA) cluster analysis was then performed, under the premise that the hierarchy of the analysis was at the population rather than individual level, on a distance matrix based on Nei's (1979) unbiased minimum distances derived from the RAPD data. The resulting dendrogram was bootstrapped, with 1000 replicates, to test the robustness of the observed population divisions. Finally, a series of Mantel tests were performed between the geographical distances between the populations and the $\Phi_{\mathrm{ST}} \mathrm{S}$, Slatkin's (1985) linearised $F_{\mathrm{ST}} \mathrm{S}$, and results derived from the UPGMA analysis, to examine the correlation, if any, between genetic phenotype and geographical distance.

\section{RESULTS}

\section{Population dynamics}

Population densities of Abra tenuis, at Transects 1 and 2, fluctuated wildly by up to 2 orders of magnitude in the March samples and by up to 3 orders of magnitude in the August samples, over the whole sampling period (Fig. 2). In general, the density of $A$. tenuis was always at least an order of magnitude greater in the August than in the
March samples (Fig. 2), with A. tenuis being encountered in almost all of the August samples but in approximately half of the March samples (Fig. 2). For 2 periods, 1987 to 1989 and in 1994, sampling in March and August (Fig. 2) failed to reveal the presence of any A. tenuis. After these periods A. tenuis reappeared in the August samples (i.e. 1990 and 1995) as 1 yr old individuals (Fig. 3). In effect, re-colonisation of both sites must have occurred after localised extinction events, persisting for periods of 3 and $1 \mathrm{yr}$, respectively (Figs. 2 \& 3). Recruitment post-1990 and post-1994, i.e. after the extinction events, was rapid, with the population densities returning to normal levels by the preceding years (Fig. 3).

\section{Population genetics (RAPD analysis)}

From the 234 individuals of the 7 populations/subpopulations studied, the 6 primers amplified a total of

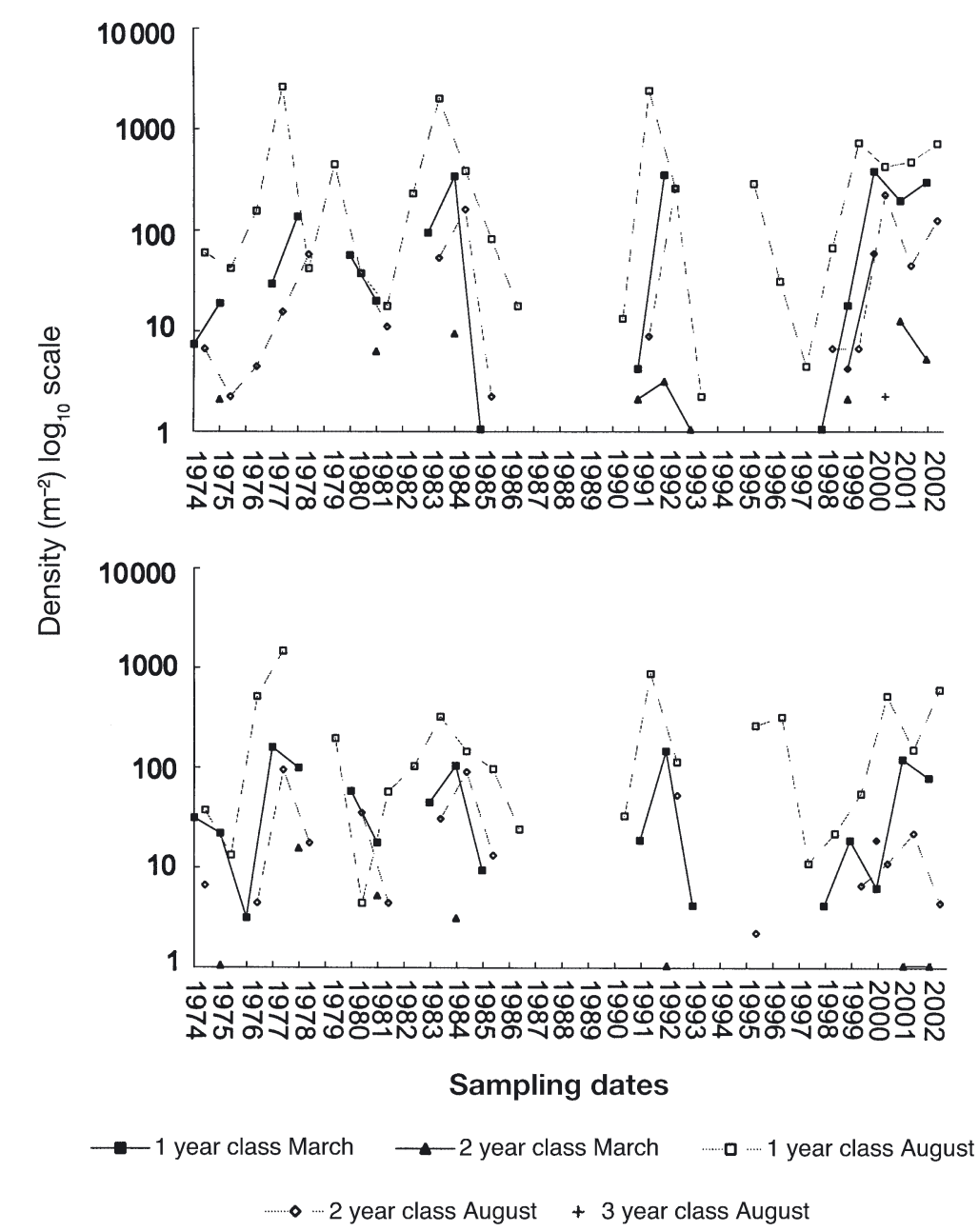

Fig. 3. Density of year classes for Abra tenuis for both transects (data pooled) over the whole sampling period 


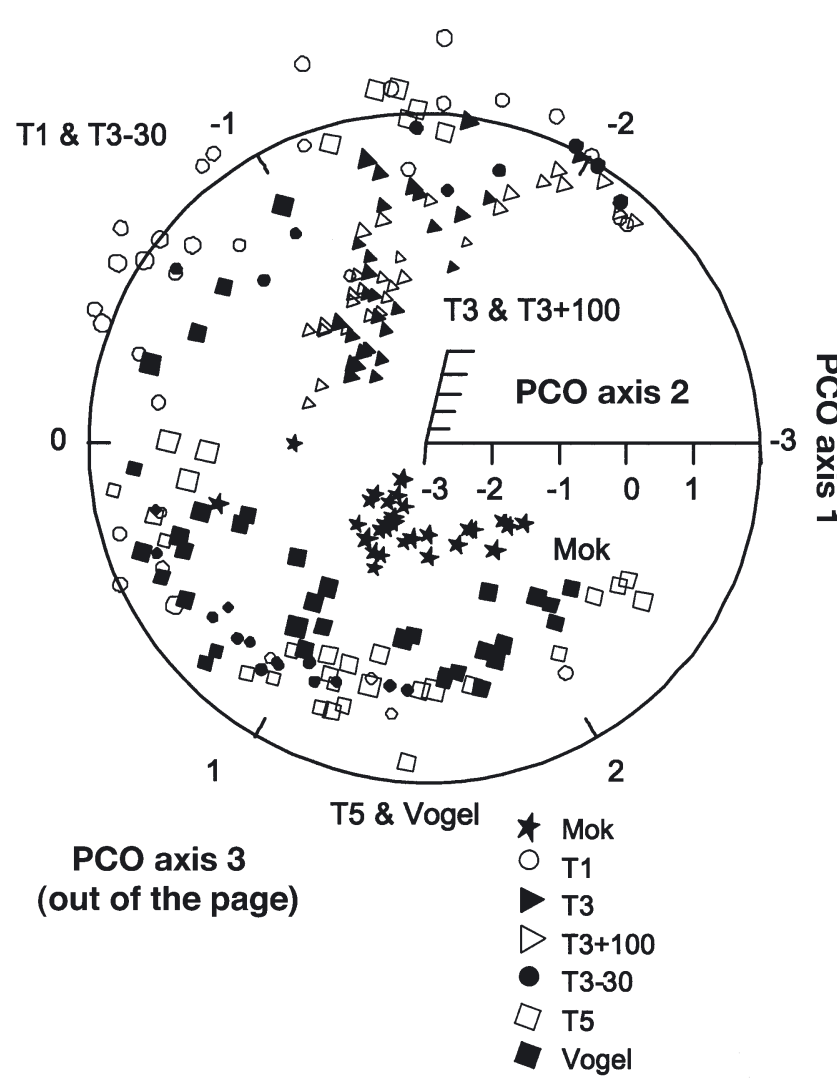

Fig. 4. Cylindrical plot of the first 3 axes derived from the PCO analysis showing the distribution of the 7 populations

50 different polymorphic fragments (Table 2). A complete data set including band frequencies are available at www.sebby.co.uk/data.html. In general, all primers yielded population-specific fragments, although both the frequency and exact differentiation (i.e. the presence of bands unique to any 1 population) of such fragments/bands varied between primers. Analysis of the data using PCO resulted in the extraction of 4 factors, which accounted for $\sim 21, \sim 10, \sim 8$ and $\sim 6 \%$, respectively, of the total variance. A plot of these factors, only the first 3 are shown, reveals that the Mok population appears to be different to all other populations, and that the remaining 6 populations form 3 groups, each composed of 2 populations, with each group appearing genetically distinct from all other groups: T1 and T3 - 30, T5 and vogel, and T3 and T3 + 100, respectively (Fig. 4).

Analysis of molecular variance, based on the precept, as determined from the PCO, that the Mok population and the population groups T1 and T3 - 30, T3 and T3 + 100 and T5 and vogel were all different from each other, revealed that $\sim 21 \%$ of the total variance could be attributed to between-population/ group differences, $\sim 14 \%$ to population-within-group differences, and the remaining $\sim 65 \%$ to withinpopulation differences (Table 4). Any attempt to subdivide the groups into individual populations failed to reveal the presence of any further group divisions. That is, further sub-division of the groups into populations resulted in a decrease in the betweenpopulation/-group variance $\left(\Phi_{\mathrm{CT}}\right)$, which was reflected in the among-population within-groups variance $\left(\Phi_{\mathrm{SC}}\right)$, which was always statistically significant. In effect, the majority of the variance between populations' pairwise variances $\left(\Phi_{\mathrm{ST}} \mathrm{S}\right)$, after correction for multiple comparisons, revealed that the genetic identity, as determined by the RAPD banding patterns, of the populations was in line with the population/group structure derived from the PCO. In addition, both the among- (Table 4) and between-population fixationindex values (i.e. $\Phi_{\mathrm{CT}}$ and $\Phi_{\mathrm{SC}}$ ) were reasonably high, indicating a considerable degree of genetic structuring.

Construction of a dendrogram, using UPGMA, determined, as for the PCO, that the populations could be split into 4 distinctive populations/population groups: Mok, T1 and T3 - 30, T5 and vogel, and T3 and $\mathrm{T} 3+100$, respectively. Examination of the bootstrap values obtained, for population/s ascribed to a group, revealed that for all cases it was with an accuracy $\geq$ $68 \%$ (Fig. 5), i.e. highly significant.

Mantel tests, performed to examine the correlation, if any, between genetic and geographical distances/ differences between the populations using all of the various indices, failed to reveal any discernible relationships, irrespective of the indices and/or matrix combinations and geographical distance, whether directly (as the crow flies) or indirectly via the path of water currents.

Table 4. AMOVA table for RAPD data. ${ }^{*} \mathrm{p} \leq 0.05,{ }^{* * *} \mathrm{p} \leq 0.001$

\begin{tabular}{|lccccc|}
\hline Source & df & SS & Variance & \% variance & Fixation indices \\
\hline Among groups & 3 & 495.450 & 1.972 & 20.61 & $0.206^{*}\left(\Phi_{\mathrm{CT}}\right)$ \\
Among populations within groups & 3 & 151.889 & 1.352 & 14.13 & $0.178^{* * *}\left(\Phi_{\mathrm{SC}}\right)$ \\
Within populations & 227 & 1417.413 & 6.244 & 65.26 & $0.347^{* * *}\left(\Phi_{\mathrm{ST}}\right)$ \\
Total & 233 & 2064.752 & 9.568 & & \\
\hline
\end{tabular}




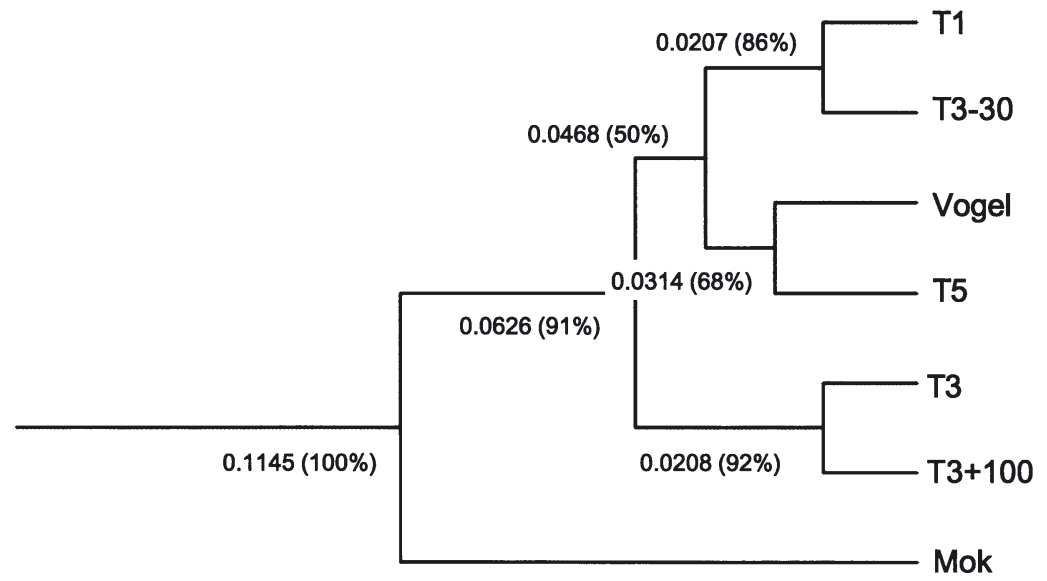

Fig. 5. UPGMA dendrogram calculated from the RAPD data where populations are defined as the level of hierarchy

\section{DISCUSSION}

Analysis of the population-dynamics data revealed that the density of Abra tenuis fluctuated wildly between years, with 2 extinction events being recorded. Similar observations for large annual variations in the density of $A$. tenuis have been noted by Gibbs (1984) and Bachelet (1989) for studies carried out over much shorter time periods, i.e. 2 to 3 yr (see also Dekker \& Beukema 1993, 1999). Two explanations, in the absence of the consideration of the genetic data, exist for the recovery of the populations following their extinction. The first explanation, in line with that suggested by Dekker \& Beukema (1993), is that population recovery has occurred through the reproductive efforts of a few remaining aggregated adults that are overlooked by the sampling methodology. It should be noted that any surviving individuals have to be highly aggregated to contribute population recovery, given the mode of reproduction adopted by $A$. tenuis. The second explanation is that dispersal has occurred from other extant populations, resulting in the recolonisation of the denuded transects. Examination of the population genetic data, which revealed that populations separated by $3 \mathrm{~km}$ were genetically similar, suggests that the latter explanation is the most appropriate. The ability of species that produce aplanic larvae, and therefore under conventional wisdom have no broadcast capacity to disperse, has been well documented in the literature. For example, Johannesson (1988) showed that all of the organisms colonising an extremely isolated patch of the subtidal were a/anchiplanic species. For such species, post-metamorphic, juveniles and/or adults can act as the dispersive stage (Highsmith 1985, Olivier et al. 1996, Wilhelmsen 1998, Hendler et al. 1999).
In terms of the population dynamics of a species, Van der Meer et al. (2001) have shown that non-larval (juvenile/adult) dispersal can have a major impact in determining the stability and density of future adult stocks. Because the studied populations both recovered rapidly, following crashes, and exhibited considerable variability in population density, this would suggest that the level of dispersal between the different populations is both low and extremely population specific, which is verified by the results of the population genetics. For the populations studied, winter temperature is likely to be the major cause for extinction events, i.e. this will have the greatest effect on future (i.e. spring) densities (see Dekker \& Beukema 1993, 1999). However, for other populations in less climatically variable environments (i.e. where such populations are not at their geographical limit), infection by digenean parasites, which render the host infertile (Campbell 1985), are likely to have the greatest structuring effect (see Gibbs 1984, Bachelet 1989).

Analysis of the population genetic data revealed that the 7 populations could be split up into 4 populations/population groups (i.e. Mok, T1 and T3 - 30, T3 and T3 + 100, and T5 and vogel), genetically identical within their group but genetically distinct from each other. Correspondingly, several studies on the population genetics of a/anchiplanic species have revealed, in line with these results, that different populations can be genetically identical rather than dissimilar (see France et al. 1993, Grant \& Silva-Tatley 1997, O' Foighil \& Jozefowicz 1999). These results establish that dispersal does occur between different populations of Abra tenuis. The evidence for this from the genetic data is 2 -fold. Firstly, analysis of the results obtained from the population genetic analysis revealed, contrary to the predictions of the panmictic hypothesis, that all of the populations were not genetically distinct from each other, i.e. dispersal/mixing must have occurred. Even if the 5 populations from the sluice site are considered as sub-populations of each other, the genetic evidence reveals that there is no genetic difference between the T5 and the vogel populations, which are both physically separated by a persistent body of water and by a geographical distance of $\sim 3 \mathrm{~km}$. Under the panmictic precept, the sluice populations should be different from all other populations, irrespective of whether or not we consider them as individual populations or subpopulations. Secondly, in the absence of dispersal, if extinction events occur on a semi-regular basis, as indicated by the population dynamic data, it is inevitable that populations would be driven towards a genetic 
bottleneck. If founder events had occurred, we would expect very high $\Phi_{\mathrm{ST}}\left(F_{\mathrm{ST}}\right)$ values to arise from the AMOVA, which is not the case. Note that the fixation indices derived from the AMOVA are not accurate when used for the analysis of haplotypic data and, hence, should be regarded as indicators rather than absolute values (Schneider et al. 2000).

Given that dispersal occurs resulting in the formation of both genetically distinct populations/population groups and genetically similar population groups, it is envisaged that recovery/re-colonisation of denuded sites occurs in the following manner. Where extinction occurs, a few widely dispersed individuals remain, which act as the host-site stock. Dispersal from other sites results in the formation of a few groups of aggregated individuals composed of both external recruits and the existing stock. These groups then give rise to future populations, resulting in site recovery. Under this premise, explanation of the results for both the population dynamic and genetic data can be made as follows. Freezing conditions in winter will be the main factor structuring the following year's population density (Dekker \& Beukema 1993, 1999), with cold winters resulting in death of the majority of individuals. From the population dynamic data (Fig. 2) it is apparent that for slightly more than half the March samples, the density of Abra tenuis has fallen below our detection limit, in addition to which there are 2 extinction events (1987 to 1989, and 1994). Under freezing conditions only the large $(>6 \mathrm{~mm}) A$. tenuis will survive the winter (T. Compton pers. comm.), thereby severely restricting the population's breeding potential. Because A. tenuis fertilises externally, breeding individuals have to be closely spaced (of the order of $\mathrm{cms}$ ) to ensure fertilization. Genetic differences between populations were detected at a microscale $(30+\mathrm{m})$ and therefore, dispersal has to occur in a geographically specific manner, i.e. if dispersal was efficient, and at a large scale, given time all populations would become mixed and hence genetically indistinguishable. Periodic population crashes, irrespective of external recruitment, will then give rise to genetically differentiated populations/ groups by the processes of inbreeding and highly directional dispersal. Any successful recruits to a population/group will effectively become incorporated and assimilated into that population, adding to the within-population variance.

With regard to the possible vectors responsible for dispersal, we believe there are two: transport by waterfowl, and transport by prevailing tidal currents, with both mechanisms serving to passively transport Abra tenuis. For the first vector, inadvertent ingestion and transport by waterfowl species will ensure that surviving A. tenuis are deposited in the faeces of the bird as it moves from one feeding site to another.
Cadée (1994) has shown that small Hydrobia ulvae consumed by the shelduck Tadorna tadorna can survive passage through the gut (see also Kew 1893, Wesselingh et al. 1999), whilst Bartoli (1982) and Campbell (1985) have shown that $A$. tenuis can act as the first and secondary intermediate host of the digenean parasite Gymnophallus rebecqui. The definitive host is therefore waterfowl, thereby giving a parsimonious nature to the proposed relationship (see also Wilhelmsen 1998, Reise 2003). With regard to the second vector, many studies have shown that larvae/juveniles can be transported by currents and deposited in sitespecific areas according to physical characteristics of both the larvae/juveniles and the prevailing water currents (see reviews by Butman 1987 and Snelgrove \& Butman 1994 for details). For example, juveniles scoured from the sediment at one site by water currents are likely to be deposited at another site inhabited by A. tenuis, given that there is a reduction in the current velocity and the presence of similar sites of deposition.

In terms of the inter-relationship between the populations, if it is assumed that both waterfowl and prevailing tidal currents are the vector of transport, an explanation can be made as follows. The vogel site is a roost for waterfowl, and T5 fringes a dense cockle Cerastoderma edule bed, which is the most locally favourable feeding ground. Both sites are the first to be inundated by an incoming tide with a permanent channel running between the two. T1 and T3 - 30 are the next 2 sites to be flooded by the tides, with strong rip currents along their edges, and hence there should be horizontal transport between these sites, and a biomass less than that of T5. T3 and T3 +100 are flooded at approximately the same time from either side, and hence there should be some transport between the sites. Fowl will spend the majority of their time feeding at $\mathrm{T} 5$ before retuning back to their roost (vogel). Less successful birds will be forced to forage at T1 and T3 30 , and then at $\mathrm{T} 3$ and $\mathrm{T} 3+100$ where the nutritional value of the biomass is the lowest. In terms of the results, clustering of the sluice and vogel populations within the same approximate areas (PCO), and on a common branch (UPGMA analysis) (Figs. 4 \& 5), will result both from the feeding patterns of the fowl and of the interconnection between the sites by the common channel. The Mok population, which effectively forms and outgroup, is not visited by any of the feeding fowl and is too far away to be influenced by the currents originating from the sluice site. The similarity of the T1 and T3 - 30 populations results from horizontal transport along the shore, and the similarity of the T3 and T3 + 100 results from vertical transport arising from simultaneous flooding of the tidal flat from both sides. Although this is little more than speculation, a link can be drawn between the potential dispersal vectors and 
the relatedness of the populations. It would explain why no correlation could be obtained between geographical and genetic distance. However, it may be that the population genetic structure has not been examined on a sufficiently large spatial scale.

In summary, examination of the population dynamics of Abra tenuis at 2 sites for $\sim 30 \mathrm{yr}$ reveals that, despite its mode of reproduction, population density is highly variable from year to year, and that extinction events have occurred. Analysis of the population genetic data determined, in contrast to the panmictic precept, that geographically distinct populations were related, i.e. dispersal does occur in this species. The suggested vectors for the dispersal of $A$. tenuis include ingestion by marine fowl and transport by prevailing water currents. The implications of these results are important because they illustrate how species that are constrained by virtue of their biology/ecology and/or evolution to a particular mode of reproduction (i.e. a/anchiplanic strategies) still manage to successfully disperse/colonise habitats and deviate from the presumptions of the panmictic paradigm.

Acknowledgements. We would like to note that this research was funded by an ALW grant (No: 88510314) held by S.P.H. In addition we would like to thank one of the anonymous referees, whose efforts greatly improved the quality of this paper.

\section{LITERATURE CITED}

Bachelet G (1989) Recruitment in Abra tenuis (Montagu) (Bivalvia, Semelidae), a species with direct development and a protracted meiobenthic phase. In: Ryland JS, Tyler PA (eds) Reproduction, genetics and distribution of marine organisms. Olsen \& Olsen, Fredensborg, p 23-30

Bartoli P (1982) Gymnophallus rostratus n. sp. (Trematoda: Gymnophallidae) parasite de Lamellibranches marins de Camargue (France). Vie Marine 4:51-58

Beukema JJ (1993) Successive changes in the distribution patterns as an adaptive strategy in the bivalve Macoma balthica (L.) in the Wadden Sea. Helgol Meeresunters 47: 287-304

Butman CA (1987) Larval settlement of soft-sediment inverterbrates: the spatial scales of pattern explained by active habitat selection and the emerging role of hydrodynamical processes. Ocean Mar Biol Annu Rev 25:113-165

Cadée G (1994) Eider, shelduck and other predators, the main producers of shell fragments in the Wadden sea: palaeoecological implications. Palaeontology 37:181-202

Campbell D (1985) The life cycle of Gymnophallus rebecqui (Digenea: Gymnophallidae) and the response of the bivalve Abra tenuis to its metacercariae. J Mar Biol Assoc UK 65:589-601

Crisp DJ (1976) The role of pelagic larvae. In: Spencer-Davis $\mathrm{P}$ (ed) Perspectives in experimental zoology. Pergamon Press, Oxford, p 145-155

Dekker R, Beukema JJ (1993) Dynamics and growth of a bivalve, Abra tenuis, at the Northern edge of its distribution. J Mar Biol Assoc UK 73:497-511

Dekker R, Beukema JJ (1999) Relations of summer and winter temperatures with dynamics and growth of two bivalves, Tellina tenuis and Abra tenuis, on the northern edge of their intertidal distribution. J Sea Res 42:207-220

Excoffier L, Smouse PE, Quattro JM (1992) Analysis of molecular variance inferred from metric distances among DNA haplotypes: application to human mitochondrial DNA data. Genetics 131:479-491

Farrell TM (1991) Models and mechanisms of succession. An example from a rocky intertidal community. Ecol Monogr 61:95-113

France SC, Hessler RR, Vrijenhoek RC (1993) Genetic differentiation between spatially disjunct populations of the deep-sea, hydrothermal vent-endemic amphipod Ventiella sulfuris. Mar Biol 114:551-559

Gaines SD, Lafferty KD (1995) Modelling the dynamics of marine species: the importance of incorporating larval dispersal. In: McEdward (ed) Ecology of marine invertebrate larvae. CRC Press, Boca Raton, FL

Gaines MS, Caldwell J, Vivas AM (1974) Genetic variation in the mangrove periwinkle, Littorina angulifera. Mar Biol 27:327-332

Gibbs PE (1984) The population cycle of the bivalve Abra tenuis and its mode of reproduction. J Mar Biol Assoc UK 64:791-800

Gooch JL, Smith BS, Knupp D (1972) Regional survey of gene frequencies in the mud snail Nassarius obsoletus. Biol Bull 142:36-48

Grant WS, Silva-Tatley da FM (1997) Lack of genetically-subdivided population structure in Bullia digitalis, a southern African marine gastropod with lecithotrophic development. Mar Biol 129:123-137

Havenhand H (1995) Evolutionary ecology of larval types. In: McEdward L (ed) Ecology of marine invertebrate larvae. CRC Press, Boca Raton, FL, p 79-122

Hendler G, Baldwin CC, Smith DG, Thacker CE (1999) Planktonic dispersal of juvenile brittle stars (Echinodermata: Ophiuroidea) on a Caribbean reef. Bull Mar Sci 65: 283-288

Highsmith R (1985) Floating and algal rafting as potential dispersal mechanisms in brooding invertebrates. Mar Ecol Prog Ser 25:169-179

Holmes SP, Miller N, Weber A (2002) The respiration and hypoxic tolerance of Nucula nitidosa and N. nucleus: factors responsible for determining their distribution? J Mar Biol Assoc UK 82:971-981

Huang BX, Peakall R, Hanna PJ (2000) Analysis of genetic structure of blackslip abalone (Haliotis rubra) populations using RAPD, minisatellite and microsatellite markers. Mar Biol 136:207-216

Hunt A (1993) Effects of contrasting patterns of larval dispersal on the genetic connectedness of local populations of two intertidal starfish, Paitriella calcar and P. exigua. Mar Ecol Prog Ser 92:179-186

Istock CA (1967) The evolution of complex life cycle phenomena: an ecological perspective. Evolution 21:592-605

Johannesson K (1988) The paradox of Rockall: why is a brooding gastropod (Littorina saxatilis) more widespread than one having a larval dispersal stage (L. littorea)? Mar Biol 99:507-513

Kew HW (1893) The dispersal of shells. Trubner \& Co, London

Kim I, Yoon MH, Min BY, Kim DH (2000) Gene flow of the blue mussel (Mytilus edulis) species complex in Korea detected by mitochondrial COI II gene sequences. Korean J Gen 22:305-318

Lewontin R (1965) Selection for colonising ability: In: Baker HG, Stebbins GL (eds) The genetics of colonising species. Academic Press, New York, p 71-99 
Lindquist N, Hay ME (1996) Palatability and chemical defence of marine invertebrate larvae. Ecol Monogr 66: 431-450

Menge BA (1975) Brood or broadcast? The adaptive significance of different reproductive strategies in the two intertidal sea stars Leptasterias hexactis and Pisaster ochraceus. Mar Biol 31:87-100

Menge BA (1995) Indirect effects in marine rocky intertidal interaction webs: patterns and importance. Ecol Monogr 65:21-74

Mileikovsky SA (1971) Types of larval development in marine bottom invertebrates, their distribution and ecological significance: a re-evaluation. Mar Biol 10:193-213

Nei M (1978) Estimation of average heterozygosity and genetic distance from a small number of individuals. Genetics 89:583-590

Nott PL (1980) Reproduction in Abra alba (Wood) and Abra tenuis (Montagu) (Tellinacea: Scrobiculadriiade). J Mar Biol Assoc UK 60:465-479

O'Foighil D, Jozefowicz CJ (1999) Amphi-Atlantic phylogeography of direct-developing lineages of Lasaea, a genus of brooding bivalves. Mar Biol 135:115-122

Olivier F, Vallet C, Dauvin J, Retiere C (1996) Drifting in postlarvae and juveniles in an Abra alba (Wood) community of the eastern part of the Bay of Seine (English Channel). J Exp Mar Biol Ecol 199:89-109

Palumbi SR (1995) Using genetics as indirect estimator of larval dispersal. In: McEdward L (ed) Ecology of marine invertebrate larvae. CRC Press, Boca Raton, FL, p 369-412

Palumbi SR (1996) Nucleic acids II: the polymerase chain reaction. In: Hillis DM, Mortiz C, Mable BK (eds) Molecular systematics. Sinauer Associates, Sunderland, MA

Palumbi SR, Kessing B (1991) Population biology of Transarctic exchange: MtDNA sequence similarity between Pacific and Atlantic sea urchins. Evolution 45:1790-1805

Pechenik JA (1979) Role of encapsulation in invertebrate life histories. Am Nat 114:859-870

Editorial responsibility: Otto Kinne (Editor),

Oldendorf/Luhe, Germany
Pechenik JA (1999) On the advantages and disadvantages of larval stages in benthic marine invertebrate life cycles. Mar Ecol Prog Ser 177:269-297

Reise K (2003) Metapopulation structure in the lagoon cockle Cerastoderma lamarcki in the northern Wadden Sea. Helgol Mar Res 56:252-258

Schneider S, Roessli D, Excoffier L (2000) Arlequin ver. 2.000: a tool for population genetics data analysis. Genetics and Biometry Laboratory, University of Geneva

Slatkin M (1985) Gene flow in natural populations. Annu Rev Ecol Syst 16:393-430

Snelgrove PVR, Butman CA (1994) Animal-sediment relationships revisited: cause versus effect. Ocean Mar Biol Annu Rev 32:111-117

Tebble N (1966) British bivalve seashells. The British Museum (Natural History), London

Thorson G (1950) Reproduction and larval ecology of marine bottom invertebrates. Biol Rev 25:1-45

Todd CD, Doyle RW (1981) Reproductive strategies of marine invertebrates: a settlement timing hypothesis. Mar Ecol Prog Ser 4:75-83

Van der Meer J, Beukema JJ, Dekker R (2001) Long-term variability in secondary production of an intertidal bivalve population is primarily a matter of recruitment variability. J Anim Ecol 70:159-169

Wang WX, Widdows J (1993) Calorimetric studies on the energy metabolism of an infaunal bivalve, Abra tenuis, under normoxia, hypoxia and anoxia. Mar Biol 116:73-79

Wesselingh FP, Cadée GC, Renema W (1999) Flying high: on the airborne dispersal of aquatic organisms as illustrated by the distribution histories of the gastropod genera Tryonia and Planorbarius. Geol Mijn 78:165-174

Wilhelmsen U (1998) Rapid colonization of new habitats in the Wadden Sea by the ovoviviparous Littorina saxatilis (Olivi). Helgol Meeresunters 52:325-355

Wray GA, Raff RA (1991) The evolution of developmental strategy in marine invertebrates. TREE 6:45-50

Submitted: April 14, 2003; Accepted: November 18, 2003

Proofs received from author(s): March 1, 2004 